\title{
SPC212 Human Mesothelioma Cell Underwent Apoptosis, Oxidative Stress, Morhological Deformation Following Astaxanthin Treatment
}

Sedat Kacar ( $\sim$ skacar@ogu.edu.tr)

Eskisehir Osmangazi Universitesi Tip Fakultesi https://orcid.org/0000-0002-0671-8529

Tuğba S. Sevimli

Eskisehir Osmangazi Universitesi

Varol Sahinturk

Eskisehir Osmangazi Universitesi Tip Fakultesi

\section{Research Article}

Keywords: Astaxanthin, SPC212, malignant pleural mesothelioma, apoptosis, cytotoxicity

Posted Date: June 21st, 2021

DOI: https://doi.org/10.21203/rs.3.rs-642906/v1

License: (c) (i) This work is licensed under a Creative Commons Attribution 4.0 International License.

Read Full License 


\section{Abstract}

Although astaxanthin (ASX) is one type of caretonoids, it is more bioactive compound than other carotenoids. Despite its utilization against different cancer types, effect of ASX on mesothelioma has yet to be well-studied. In this study, our goal is to ascertain how ASX will affect SPC212 human mesothelioma cells. First, the effective doses of ASX against SPC212 cells was uncovered by MTT test. Thereafter, with flow cytometry analysis, Annexin- $V$ and caspase $3 / 7$ assay was implemented for the evaluation of apoptotic cell death and oxidative stress test was carried out to determine how the free radicals changed. Ultimately, the cells' morphology was examined under light microscope. The effective doses of ASX were found as 50,100 and $200 \mu \mathrm{M}$. In Annexin V assay, the total apoptosis increased to around $12 \%, 30 \%$ and $\% 45$ with increasing doses of ASX. In caspase $3 / 7$ assay, the total apoptosis was around $\% 25$ and $\% 38$ at 100 and $200 \mu \mathrm{M}$. In oxidative stress analysis, ROS positive cells rose from 4.54 at the lowest dose to 86.95 at the highest dose. In morphological analysis, cellular shrinkage, decrease in cell density, swelling and vacuolations in some cells, membrane blebbing and apoptotic bodies are observed in ASX-treated cells. To conclude, the current study provided insights into the efficacy and effects of ASX against SPC212 mesothelioma cells regarding morphology, proliferation and cell death for the future studies.

\section{Introduction}

Malignant pleural mesothelioma (MPM) is an uncommon and malignant thoracic disease closely linked to exposure to asbestos and its prevalence has been on upward trend globally (Patel \& Dowell, 2016). Recently, the MPM prevalence is noted to reach a peak due to the difficulty in its early prognosis and unsatisfactory treatment modalities. Although asbestos production and its commercial use is restricted or forbidden, its exploitation is still widespread. Thus, the global incidence of MPM is predicted to rise over the next decade on the grounds that mesothelioma develops long after being exposed by inhalation (Lococo, 2021) While males have a higher incidence of disease, females have a better prognosis. Hereditary background poses a risk for the predisposition to the mesothelioma.

To date, there is no reliable or approved serum biomarker in cases where the risk of developing pleural mesothelioma is high. The diagnosis of mesothelioma pathologically is difficult. The poor prognosis of this disease is on the account of its being diagnosed in the advanced stage. In addition, the response rates and survival of the MPM patients are very low. Therefore, other treatment modalities are under investigation (Catino vd., 2019).

Astaxanthin (ASX), a ketocarotenoid, was discovered by Kuhn and Sorensen who initially extracted it from lobster (Davinelli et al., 2018). ASX is a red-orange pigment found in marine organisms, especially salmonids, shrimps and crayfish. It is known for its commercial applications in a variety of industries. ASX can be produced by some organisms including plants, bacteria and microalgae (Davinelli, Nielsen, \& Scapagnini, 2018). ASX has various biological functions; immune response enhancing, protection against oxidative stress and ultraviolet (UV) light effects, providing reproductive ability and stress 
tolerance (Donoso, González-Durán, Muñoz, González, \& Agurto-Muñoz, 2021). ASX, akin to other carotenoids including zeaxanthin, lycopene and $\beta$-carotene, has many metabolisms and physiologyassociated roles. In addition, ASX is a more bioactive compound than other carotenoids. Owing to the molecular arrangement, ASX has many characteristics that enable its utilization to improve human wellbeing. For example, it possesses a relatively stronger antioxidant capacity than its correspondences (Feng vd., 2018). Recently ASX is of great interest due to its possible versatile effects against cancer, diabetics, inflammation and oxidative stress (Faraone vd., 2020). In the last thirty years of research, it was pointed out that oxidative stress causes chronic inflammation, which leads to chronic diseases such as cancer and skin damage (Simioni vd., 2018). ASX was shown to improve oxidative stress metabolism and prevent inflammation by downregulating and inhibiting inflammatory mediators. ASX, in esophageal cancer model, reported to boost antioxidant and anti-inflammation capacity by curbing the NFKB and COX2 expressions (Cui vd., 2019). Kim et al. showed that AST performs anti-migration and anti-invasion activity in the treatment of colorectal cancer by increasing the miR-29a-3p and miR-200a levels and thus suppressing the MMP2 and ZEB1 protein levels (Cui vd., 2019). In SCC131 and SCC4 oral cancer cells and cancer model, ASX was documented to inhibit PI3K / Akt and the associated NF-B and STAT-3 signaling pathways; thereby, hampering the cancer-related symptoms. (Kowshik vd., 2019). Utilization of ASX in experimental animals with sepsis and acute lung injury, was suggested to hinder MAPK / NF-KB signaling pathway and inflammatory factors, and significantly enhance survival (Cai vd., 2019). In another study, whether ASX initiates apoptosis and boosts antioxidant activity in the colorectal carcinoma cells was evaluated. Eventually, ASX was demonstrated to enhance the upregulation of Bax and Caspase 3 and to downregulate BCL2; thus, triggering apoptosis and preventing the colorectal cancer cells' growth. Similary, in another study, ASX was documented to be capable of initiating apoptosis by augmenting the expression of apoptosis-related genes and the antioxidant enzyme levels (Hormozi, Ghoreishi, \& Baharvand, 2019). Furthermore, ASX is also reported to significantly reduced in vitro proliferation and migration rates of breast cancer cells (McCall, McPartland, Moore, Frank-Kamenetskii, \& Booth, 2018).

ASX is also documented to have some synergic effect when co-used with other proteins. For example, ASX was shown to increase its anti-cancer activity when used with human serum albumin (HSA), the most abundant blood protein in SKOV3 ovarian cancer SKOV3 cells. In this study, SKOV3 cells were given ASX + HSA to explore the effects of cell proliferation, cell cycle, and drug resistance. ASX + HSA treatment was shown to increase the anticancer effects of AST, reduce G1 phase cell cycle and induce apoptosis in SKOV3 cells. (Su vd., 2019). Another example of synergic effect of ASX, Chen et al. evaluated ASX and erlotinib for Xeroderma pigmentosum C (XPC) expression-mediated cytotoxicity in non-small cell lung cancer (NSCLC) cells. Activation of p38 MAPK with ASX reduced XPC expression in lung adenocarcinoma cells. Inhibition of p38 MAPK activity decreases cytotoxicity and cell growth inhibition and destruction of XPC using siRNA increased the cytotoxic effects of ASX (Chen vd., 2018). In another study, co-teatment of ASX cand anti-cancer drug carbendazim (Carb) to MCF-7 breast cancer cells increased the antiproliferative effect of Carb treatment alone and reduced G2/M phase cell cycle and decreased intracellular ROS levels (Atalay, Kuku, \& Tuna, 2019). 
SPC212 human mesothelioma cells are suitable cell lines being a model cell line for MPM, which are derived from malignant mesothelioma a 47-year old female patient, exposed to asbestos and with a biphasic tumour of the pleural cavity. To the best of our knowledge there is no study investigating the effect ASX on these particular cell line and exploring its effective concentration. To fill this lacuna, we proposed carrying out research to unravel how different doses of ASX will affect SPC212 human mesothelioma cells.

\section{Materials And Methods 2.1 Cell Culture}

Human mesothelioma cells (SPC212) were grown in Dulbecco's modified Eagle's medium medium containing $1 \%$ penicillin-streptomycin, $10 \%$ fetal bovine serum at $5 \% \mathrm{CO}^{2}$ and $95 \%$ relative humidity at $37^{\circ} \mathrm{C}$ in culture medium. When the culture flask has a cell density of $70 \%$ (about $2-3$ days) it is separated into subcultures. Before doing this, the old medium of SPC212 cells was removed by washing the adhered cells' surface 2 times with $1 \mathrm{~mL}$ of PBS. Then the cells were dislodged by 1 min- treatment with Trypsin-EDTA, and then appropriately subcultured.

\subsection{Cytotoxicity Analysis}

Effect of ASX on cell viability of SPC212 cells were evaluated by MTT colorimetric assay. The cells were always incubated for 24 hours at $37^{\circ} \mathrm{C}$ in $95 \%$ relative humidity in a $5 \% \mathrm{CO}_{2}$ incubator. The cells were seeded at a density of $5 \times 10^{3}$ per well in the 96 -well plates. ASX was dissolved in the cell medium (Gibco, Germany) at various concentrations and applied to the cells. Plates were incubated for 24, 48,72 hours at $37^{\circ} \mathrm{C}$ in $95 \%$ relative humidity in a $5 \% \mathrm{CO}_{2}$ incubator. At the end of the incubation periods, MTT stain was added to each well. The plates with MTT dye were kept in the incubator for 2-4 hours. At the end of 2-4 hours, medium was removed from the plates and DMSO was added to dissolve the formazan crystals and placed on an orbital shaker in the dark. Microplate reader (BIOTEK ELx808IU, USA) was spectrophotometrically read at $540 \mathrm{~nm}$ wavelength and the effective doses of ASX are determined statistically by comparing the treated groups with the control group.

\subsection{Annexin V test}

Annexin V assay was accomplished in compliance with the manufacturer's instructions of the kit. The SPC212 cell line was cultivated in six-well plates and The cells were applied the different doses of ASX including 50, 100 and $200 \mu \mathrm{M}$. After $24 \mathrm{~h}$ SPC212 cells were dislodged from plates with trypsin-EDTA and taken into $1.5 \mathrm{ml}$ tubes. The SPC212 cells were gained in the bottom of the tubes by 5 -min centrifugation at $300 \times \mathrm{g}$. Next, the pellet was re-suspended by ready-to-use medium $(100 \mu \mathrm{L})$ and blended with annexin $\mathrm{V}$ and left to a $20 \mathrm{~min}$ incubation at dark at $24^{\circ} \mathrm{C}$. In the end, the results are evaluated by Muse ${ }^{\mathrm{TM}} \mathrm{Cell}$ Analyser.

\subsection{Caspase 3/7 Assay Results}


Caspase 3 and 7 dual activity was evaluated by a commercial caspase $3 / 7$ kit (Muse ${ }^{\mathrm{TM}}$ Caspase-3/7 kit, Merck Millipore, Hayward, CA, USA) based on flow cytometry. Concisely, SPC212 cells were cultivated in six-well plates and allotted into 3 groups as untreated and two ASX -treated groups (100 and $200 \mu \mathrm{M})$. After treatment and cell detachment, caspase working solution provided by kit was prepared by mixing caspase $3 / 7$ reagent and PBS (1:8). Thereafter, caspase 7-AAD working solution provided by kit was prepared by taking $2 \mu \mathrm{L}$ of 7-AAD, a cell death marker, and mixing it with $148 \mu \mathrm{L}$ buffer solution. Next, 5 $\mu \mathrm{L}$ of caspase working solution was added to $50 \mu \mathrm{L}$ of cell suspension and incubated for 30 minutes at $37^{\circ} \mathrm{C}$. Finally, $150 \mu \mathrm{L}$ of 7-AAD working solution was added to the suspension and the caspase activity in cell suspension was evaluated via Muse ${ }^{\mathrm{TM}}$ Cell Analyzer.

\subsection{Oxidative stress}

Oxidative stress was gauged according to the manufacturer's instructions. The SPC212 cell line was cultivated in six-well plates and administered with 50, 100 and $200 \mu \mathrm{M}$ of ASX. After $24 \mathrm{~h}, \mathrm{SPC} 212$ cells were dislodged from plates with trypsin-EDTA and taken into $1.5 \mathrm{ml}$ tubes. Once the SPC212 cells were gained in the bottom of the tubes by 5 -min centrifugation at $300 \times \mathrm{g}$, they were diluted with provided buffer in the kit at a cells density of $1 \times 10^{6}-1 \times 10^{7} / \mathrm{mL}$. Next, this mixture was blended with the working solution procured by the kit with a ratio of 1:19 $(10 \mu \mathrm{l}+190 \mu \mathrm{l}$, respectively). Followingly, SPC212 cells were incubated at $37^{\circ} \mathrm{C}$ for 30 min, and analysed by Muse ${ }^{\text {TM }}$ Cell Analyser (Merck, Millipore, Hayward, CA, USA).

\subsection{Hematoxylin - Eosin Staining}

Hematoxylin-eosin stain is regularly exploited for investigating morphological alterations of cells regarding cytoplasmic and nuclear as well as extracellular matrix-related modifications. The morphological alterations of ASX-treated cells were observed by hematoxylin and eosin stain. Initially, SPC212 cells were grown in 6-well plates at a density of $3 \times 10^{5}$ and treated with 50,100, 200 and $300 \mu \mathrm{M}$ of ASX for $24 \mathrm{~h}$. After that, the cells were exposed to a $10 \mathrm{~min}$-fixation with pure ice-cold methanol, followed with incubation in haematoxylin and eosin stains, respectively for $5 \mathrm{~min}$ each. Then the cells were dipped into 1\% ammonia solution for 1 min. Finally, the cells were rinsed in PBS and examined under a light microscope.

\subsection{Statistical Analysis}

First, we checked the data whether it is normally distributed or not. Shapiro-Wilk test showed that all the data follows normal distribution. Therefore, one-way analysis of variance (ANOVA) was exploited to unravel the significant difference between the groups. Levene's test confirmed the equality of variance of the data; therefore, as a post-hoc multiple comparison test, we utilized Tukey's test. The p-values less than 0.05 were deemed as statistically significant. All statistical analyses were implemented by means of the GraphPad Prism 7.0 statistical software (San Diego, CA). All statistical analyses were employed by one-way analysis of variance (ANOVA) followed by using $p<0.05$ was considered significant. All the findings were displayed as mean \pm SD (standard deviation). All the results are displayed as mean \pm S.D.

\section{Results}




\subsection{MTT Assay Results}

The anti-proliferative effect of ASX on SPC212 cells was ascertained through MTT test, as displayed in Fig. 1 and Table 1.7 different doses of ASX were applied at four time intervals including 24, 48, 72 and 96 hours. As a results of cytotoxicity test, as for 24-hour treatment, at the concentrations of ASX under 50 $\mu \mathrm{M}$, no significant decline in cell viability was detected. On the other hand, at the doses of $50 \mu \mathrm{M}, 100 \mu \mathrm{M}$ and $200 \mu \mathrm{M}$ (all $p<0.001 \mathrm{vs}$ control), significant inhibition on the proliferative activity of SPC212 cells was detected. At the maximal applied dose, $200 \mu \mathrm{M}$ cell viability dropped to $54.3 \%$. As for 48 -hour treatment, no significant change in cell viability was identified until the dose of $25 \mu \mathrm{M}$, where the cell viability was $83.7 \%$ ( $p<0.05$ vs control). At the doses of 50,100 and $200 \mu \mathrm{M}$, cell viabilities decreased to $69.3,57.9$ and $48.7 \%$, respectively (all $p<0.001$ vs control). As for 72 -hour treatment, no significant decrease in cell viability was identified until the dose of $12.5 \mu \mathrm{M}$, where the cell viability was $86.7 \%(\mathrm{p}<$ 0.05 vs control). At the doses of 25,50 and $100 \mu \mathrm{M}$, cell viabilities decreased to $81.2,59.5$ and $51.7 \%$, respectively (all $p<0.001$ vs control). At the maximal applied dose, $200 \mu \mathrm{M}$ cell viability dropped to almost $37.9 \%$ ( $p<0.001$ vs control). In the 96 -hour treatment, similarly, no significant decrease in cell viability was observed until the dose of $12.5 \mu \mathrm{M}$. At the doses of 25,50 and $100 \mu \mathrm{M}$, cell viabilities decreased to $77.6,49.6$ and $49.8 \%$, respectively (all $p<0.001$ vs control). At the highest applied dose, 200 $\mu \mathrm{M}$ cell viability dropped to almost $27.7 \%$. \%50 inhibitory concentrations of ASX against SPC212 mesothelioma cells were found as $241.7 \mu \mathrm{M}, 185.6 \mu \mathrm{M}, 112.3 \mu \mathrm{M}$ and $73.3 \mu \mathrm{M}$ for 24, 48, 72 and 96-hour long experiments, respectively. 
Table 1

The cell viability percentages of SPC212 mesothelioma cells after ASX application for 24, 48,72 anf 96 hours $(0-200 \mu \mathrm{M})$.

\begin{tabular}{|c|c|c|c|c|}
\hline \multirow[t]{2}{*}{$\begin{array}{l}\text { Astaxanthin } \\
\text { Doses }(\mu \mathrm{M})\end{array}$} & \multicolumn{4}{|c|}{$\begin{array}{l}\text { Cell Viability (\%) } \\
(\text { mean } \pm s d)\end{array}$} \\
\hline & $24 \mathrm{~h}$ & $48 \mathrm{~h}$ & $72 \mathrm{~h}$ & $96 \mathrm{~h}$ \\
\hline Control & $100.0 \pm 5.4$ & $100.0 \pm 4.8$ & $100.0 \pm 4.2$ & $100.0 \pm 4.0$ \\
\hline 3.125 & $100.2 \pm 3.6$ & $100.9 \pm 3.6$ & $98.9 \pm 4.0$ & $91.8 \pm 6.4$ \\
\hline 6.250 & $100.3 \pm 2.1$ & $93.0 \pm 3.7$ & $89.8 \pm 6.7$ & $89.1 \pm 5.2$ \\
\hline 12.50 & $99.5 \pm 6.2$ & $92.2 \pm 4.6$ & $86.7 \pm 7.4^{\mathrm{a}}$ & $84.4 \pm 3.5^{a}$ \\
\hline 25.00 & $90.6 \pm 4.0$ & $83.7 \pm 6.1^{\mathrm{a}}$ & $81.2 \pm 1.1^{b}$ & $77.6 \pm 3.6^{b}$ \\
\hline 50.00 & $76.6 \pm 1.8^{b}$ & $69.3 \pm 4.9^{b}$ & $59.5 \pm 3.6^{b}$ & $49.6 \pm 9.0^{b}$ \\
\hline 100.00 & $64.5 \pm 4.9^{b}$ & $57.9 \pm 5.4^{b}$ & $51.7 \pm 1.7^{b}$ & $49.8 \pm 1.7^{b}$ \\
\hline 200.00 & $54.3 \pm 4.0^{b}$ & $48.7 \pm 5.2^{b}$ & $37.9 \pm 4.9^{b}$ & $27.7 \pm 6.4^{b}$ \\
\hline
\end{tabular}

\subsection{Annexin V Assay Results}

According to the Annexin $V$ findings (Fig. 2 and Table 2), the cell viability was detected as $97.26 \%$ in untreated SPC212 cells, while the total apoptotic cell rate was $1.58 \%$ (early apoptosis rate $0.95 \%$ and late apoptosis rate $0.63 \%)$. At $50 \mu \mathrm{M}$ of ASX, the lowest applied dose, the viability of SPC212 cells dropped to $79.42 \%$, while the ratio of total apoptotic cells was revealed to be $13.25 \%$ (early apoptosis rate $0.92 \%$ and late apoptosis rate $12.33 \%$ ). At $100 \mu \mathrm{M}$ of ASX, the viability of SPC212 cells decreased to $54.92 \%$, the ratio of total apoptotic cells was found to be $37.86 \%$ (early apoptosis rate $8.21 \%$ and late apoptosis rate $29.65 \%$ ). Eventually, at $200 \mu \mathrm{M}$ of ASX, the highest applied dose, the viability of SPC212 cells was $38.43 \%$, the total apoptosis ratio was $51.24 \%$ (early apoptosis rate $6.65 \%$ and late apoptosis rate $44.59 \%)$. 
Table 2

The percentage of cell viability and cell death in SPC212 mesothelioma cells according to Annexin V assay $(0-200 \mu \mathrm{M})$.

\begin{tabular}{|llllll|}
\hline Astaxanthin & \multicolumn{5}{l}{ Annexin V Assay (\%) } \\
\cline { 2 - 6 } Doses $(\mu \mathrm{M})$ & $\mathrm{L}$ & $\mathrm{EA}$ & $\mathrm{LA}$ & $\mathrm{TA}$ & $\mathrm{D}$ \\
\hline Control & 97.26 & 0.95 & 0.63 & 1.58 & 1.16 \\
\hline $\mathbf{5 0 . 0}$ & 79.42 & 0.92 & 12.33 & 13.25 & 7.33 \\
\hline $\mathbf{1 0 0 . 0}$ & 54.92 & 8.21 & 29.65 & 37.86 & 7.22 \\
\hline $\mathbf{2 0 0 . 0}$ & 38.43 & 6.65 & 44.59 & 51.24 & 10.33 \\
\hline L: live cells; EA: early apoptosis; LA: late apoptosis; TA: total apoptotic cells and D: dead cells. \\
\hline
\end{tabular}

\subsection{Caspase 3/7 Assay Results}

According to the Caspase 3/7 assay findings by flow cytometry (Fig. 3 and Table 3), the viability of SPC212 cells was disclosed as $98.30 \%$, and the rate of total apoptotic cells (early apoptosis ratio: $0.07 \%$ and late apoptosis ratio: $1.36 \%$ ) was $1.42 \%$. The rate of dead cells was $0.27 \%$. At $100 \mu \mathrm{M}$ of ASX, cell viability decreased to $63.25 \%$, and the ratio of total apoptotic cells (early apoptosis rate: $0.36 \%$ and late apoptosis rate: $24.84 \%$ ) was $25.20 \%$. The rate of dead cells was $11.55 \%$. At $200 \mu \mathrm{M}$ of ASX, cell viability further decreased to $45.31 \%$, and the ratio of total apoptotic cells (early apoptosis rate: $4.69 \%$ and late apoptosis rate: $37.81 \%$ ) was $42.50 \%$. The rate of dead cells was $12.19 \%$.

Table 3

The percentage of cell viability and cell death in SPC212 mesothelioma cells according to Caspase $3 / 7$ assay.

\begin{tabular}{|llllll|}
\hline Astaxanthin & \multicolumn{5}{l}{ Caspase 3/7 Assay (\%) } \\
\cline { 2 - 6 } Doses $(\mu \mathrm{M})$ & $\mathrm{L}$ & $\mathrm{EA}$ & $\mathrm{LA}$ & $\mathrm{TA}$ & $\mathrm{D}$ \\
\hline Control & 98.30 & 1.36 & 0.07 & 1.42 & 0.27 \\
$\mathbf{1 0 0 . 0}$ & 63.25 & 0.36 & 24.84 & 25.2 & 11.55 \\
\hline 200.0 & 45.31 & 4.69 & 37.81 & 42.5 & 12.19 \\
\hline L: live cells; EA: early apoptosis; LA: late apoptosis; TA: total apoptotic cells and D: dead cells. \\
\hline
\end{tabular}

\subsection{Oxidative Stress Results}

As regards the oxidative stress results as shown in Fig. 4 and Table 4, the percentages of ROS negative and positive cells were $95.46 \%$ and $4.54 \%$, respectively in control cells. In $50 \mu \mathrm{M}$ of ASX-treated cells, the percentage of ROS negative cells decreased to $86.55 \%$, while the percentage of ROS positive cells rose to $13.45 \%$. In $100 \mu \mathrm{M}$ of ASX-treated cells, ROS negative cells lowered to $64.40 \%$ while ROS positive cells further increased to $35.60 \%$. On the other hand, ultimately, in $200 \mu \mathrm{M}$ of ASX-treated cells, the ROS 
negative cells fell down to their lowest level be decreasing to $13.05 \%$ and the ROS positive cells topped among all groups with the percentage of $86.95 \%$.

\section{Table 4}

The percentage of reactive

oxygen species positive and

negative cells after astaxanthin treatments $(0-200 \mu \mathrm{M})$.

\begin{tabular}{|lll|}
\hline Astaxanthin & ROS & \multicolumn{1}{r|}{ ROS } \\
Doses $(\mu \mathrm{M})$ & $-(\%)$ & $+(\%)$ \\
\hline Control & 95.46 & 4.54 \\
\hline $\mathbf{5 0 . 0}$ & 86.55 & 13.45 \\
\hline 100.0 & 64.40 & 35.60 \\
\hline $\mathbf{2 0 0 . 0}$ & 13.05 & 86.95 \\
\hline ROS: Reactive oxygen species. \\
\hline
\end{tabular}

\subsection{Light Microscope Analysis}

Light microscope analysis was carried out with hematoxylin-eosin staining. The cells were divided into 5 different groups: control group, 50, 100, 200 and $300 \mu \mathrm{M}$ of ASX-treated cells. In the untreated group, density of cells were more than ASX-treated groups. The density of cells diminished with the ascending ASX concentrations. Furthermore, the cells and cellular cytoplasm got shrunk as the dose increased. In some ASX-treated cells, vacuole-like structures and swelling was observed. In some other cells, membrane blebbing and kidney-shaped nuclei were apparent (Fig. 10A-E).

\section{Discussion}

According to the results of our literature research; this is the first study to investigate the effect of ASX on human mesothelioma cells, SPC212.

Previous reports deduced that ASX has reduced viability of cancer cells among different types of cancer cells studied so far. In the stufy of Kim et al, the MTT assay was performed for ASX-treated (50 and 100 $\mu \mathrm{M}$ ) colon cancer cells to measure cell proliferation (Kim, Kim, \& Hong, 2019a). In another study, cytotoxic activity of ASX on A549 and $\mathrm{H} 1703$ cells was investigated. ASX reduced cell viability in a concentration and time-dependent manner. In the colony-forming test, ASX was suggested to significantly suppress the ability of A549 and H1703 cells to colonize (Ko vd., 2016). Furthermore, ASX was shown to supress proliferation of LS-180colon cancer cells and decreased the cell viability with dose-dependent manner (Hormozi vd., 2019). ASX exerted an inhibitory effect in non-small cell lung cancer (NSCLC) cell proliferation and viability (Chen vd., 2018). ASX blocked the cell proliferation in the breast cancer cells investigated (McCall vd., 2018). An appropriate concentration of ASX, is effective for preventing the 
proliferative activity of Caco-2 cells (Kim, Lim, \& Kim, 2019b). The common point in ASX toxicity studies is that ASX causes dose and time dependent cytotoxic effects on cell lines. ASX decreased SPC212 cell viability dose- and time-dependently and that IC50 value for $24 \mathrm{~h}$ ASX treatment against SPC212 cells were detected as $241.7 \mu \mathrm{M}$.

Innate oxidative stress is considered to pathophysiology of cancers because potent factor of angiogenesis. ROS is generated by aerobic cellular metabolism and scavenged by antioxidant mechanisms. ROS production and antioxidant defense capability cause oxidative stress. Oxidative stress results in cell damage (Meng, Ni, Yu, Wang, \& Shen, 2017). ASX has antioxidant, anti-inflammatory and immunomodulatory properties. Antioxidants are the focus of researches due to their anticancer properties. Previous studies of ASX reported to reduce oxidative stress and preserve metabolism (Yan vd., 2017). ASX has much more potent antioxidant than other carotenoids such as zeaxanthin, lutein, tunaxanthin, cantaxanthin and b-carotene and a-tochopherol. ASX inhibited stress in the liver by reducting of lipid peroxidation and NK cell activity. Also, ASX showed with an inhibitory effect on hepatic metastases by its antioxidative property (Kurihara, Koda, Asami, Kiso, \& Tanaka, 2002). ASX inhibited cytotoxic effects of glutamate in mouse hippocampal HT22 cell. ASX reduced cell viability, glutamateinduced caspase activation and ROS nuclear accumulation (Wen vd., 2015). Oxidative stress is an important factor in diseases such as cancer and causes to mitochondrial dysfunction. Wolf et al. analyzed basal oxidative stress, superoxide measurement and mitochondrial membrane potential. They reported that ASX decreased oxidative stress and protected HeLa cells against oxidative stress (Wolf vd., 2010).

ASX provided decreases in SOD2 level and SOD activity and reduced mitochondrial ROS in gastric epithelial AGS cells (Kim vd., 2019b). In rat glioma cells, ASX showed reactive oxygen species (ROS) and free radical salvaging properties as a quencher of singlet reactive oxygen, nitrogen and two electron oxidants (Afzal vd., 2019). ASX is a potent antioxidant and has terminal carbonyl group which is conjugated to a polyene. It scavenges free radicals. So ASX protects cells from cancer. ASX may result variously from its antioxidant and anti-cancer properties interactions with altering gene expression and cellular signalling cascades (Ambati, Phang, Ravi, \& Aswathanarayana, 2014). In our oxidative stress analysis, consistent with literature, ASX also decreased oxidative stress in a dose-dependent way in SPC212 cells

Apoptosis is an organized programmed cell death that occurs in physiological and pathological conditions. Apoptosis can be triggered either by extrinsic pathway and intrinsic pathway. During the apoptosis caspase proteins including caspase -3 , caspase -8 and -9 play critical roles. Caspase- 3 is important in this process. Wen et al. examined the activities of caspase proteins in HT22 cells. They demonstrated that glutamate generated the activation of caspase 8/9 in HT22 cells by co- treatment with ASX and ASX prevented activation of caspase-3 (Wen vd., 2015). In vitro studies using cancer cell lines and in vivo tumour models have indicated the anti-proliferative and proapoptotic effects of ASX (Liu vd., 2016; Sowmya, Arathi, Vijay, Baskaran, \& Lakshminarayana, 2017; Wu vd., 2016). ASX reduced oxidative stress and cell death in HT22 cells. ASX decreased ROS and thereby aborted intrinsic apoptosis by 
upregulating antiapoptotic Bcl-2 expression and downregulating proapoptotic Bax expression (Wen vd., 2015). Zhang et al. examined the effect of ASX and other carotenoids at the different dose ranges on K562 cells. They reported that carotenoids (b-carotene, ASX, capsanthin and bixin) decreased the viability of K562 cells and induced cell apoptosis (Zhang, Zhao, Hu, Zhao, \& Huang, 2011). Kavitha et al. evaluated the effect of ASX in the hamster buccal pouch (HBP) carcinogenesis model by caspase caspase $3 / 9$ test by enzymatic assay. ASX significantly increased the expression of caspase-9, caspase - 3 and PARP (Kavitha, Kowshik, Kishore, Baba, \& Nagini, 2013). Meng et al. reported ASX treatment is not a clear indicator of protective effects on apoptosis for RWPE-1 or PC-3 cells by Annexin V (Meng vd., 2017).

We analysed ASX's apoptotic effect on SPC212 cells after the cytotoxic and antiproliferative effect analyses. We recognized this finding by Annexin $\mathrm{V}$ and caspase $3 / 7$ analysis by flow cytometry. Annexin $V$ test and caspase $3 / 7$ assays exhibited that SPC212 cells, to which ASX was applied, were noticed to be driven to apoptosis different than control cells, which showed relatively higher viability and almost underwent no apoptosis.

In conclusion, we indicated that ASX induced growth inhibition, morphological deformation, oxidative stress and apoptosis in human mesothelioma cells and its IC50 value for SPC212 cells was found to be $241.7 \mu \mathrm{M}$ for 24 hours. We think that presented results will be an incentive for and provide new insights into future studies since there are no studies about ASX's effect on lung cancer cells.

\section{Declarations}

\section{Funding}

The authors declare that no financial support was received.

\section{Conflict of Interest}

The authors declare that there is no conflict of interests.

\section{References}

1. Afzal, S., Garg, S., Ishida, Y., Terao, K., Kaul, S. C., \& Wadhwa, R. (2019). Rat Glioma Cell-Based Functional Characterization of Anti-Stress and Protein Deaggregation Activities in the Marine Carotenoids, Astaxanthin and Fucoxanthin. Mar Drugs, 17(3). doi:10.3390/md17030189

2. Ambati, R. R., Phang, S. M., Ravi, S., \& Aswathanarayana, R. G. (2014). Astaxanthin: sources, extraction, stability, biological activities and its commercial applications--a review. Mar Drugs, 12(1), 128-152. doi:10.3390/md12010128

3. Atalay, P. B., Kuku, G., \& Tuna, B. G. (2019). Effects of carbendazim and astaxanthin co-treatment on the proliferation of MCF-7 breast cancer cells. In Vitro Cell Dev Biol Anim, 55(2), 113-119. doi:10.1007/s11626-018-0312-0 
4. Cai, X., Chen, Y., Xie, X., Yao, D., Ding, C., \& Chen, M. (2019). Astaxanthin prevents against lipopolysaccharide-induced acute lung injury and sepsis via inhibiting activation of MAPK/NF-KB. Am J Trans/ Res, 11(3), 1884-1894.

5. Catino, A., de Gennaro, G., Di Gilio, A., Facchini, L., Galetta, D., Palmisani, J., Porcelli, F., \& Varesano, N. (2019). Breath Analysis: A Systematic Review of Volatile Organic Compounds (VOCs) in Diagnostic and Therapeutic Management of Pleural Mesothelioma. Cancers (Basel), 11(6). doi:10.3390/cancers11060831

6. Chen, J. C., Wu, C. H., Peng, Y. S., Zheng, H. Y., Lin, Y. C., Ma, P. F., Yen, T. C., Chen, T. Y., \& Lin, Y. W. (2018). Astaxanthin enhances erlotinib-induced cytotoxicity by p38 MAPK mediated xeroderma pigmentosum complementation group C (XPC) down-regulation in human lung cancer cells. Toxicol $\operatorname{Res}(\mathrm{Camb}), 7(6), 1247-1256$. doi:10.1039/c7tx00292k

7. Cui, L., Xu, F., Wang, M., Li, L., Qiao, T., Cui, H., Li, Z., \& Sun, C. (2019). Dietary natural astaxanthin at an early stage inhibits $\mathrm{N}$-nitrosomethylbenzylamine-induced esophageal cancer oxidative stress and inflammation via downregulation of NFKB and COX2 in F344 rats. OncoTargets and therapy, 12, 5087-5096. doi:10.2147/0TT.S197044

8. Davinelli, S., Nielsen, M. E., \& Scapagnini, G. (2018). Astaxanthin in Skin Health, Repair, and Disease: A Comprehensive Review. Nutrients, 10(4). doi:10.3390/nu10040522

9. Donoso, A., González-Durán, J., Muñoz, A. A., González, P. A., \& Agurto-Muñoz, C. (2021). "Therapeutic uses of natural astaxanthin: An evidence-based review focused on human clinical trials". Pharmacol Res, 166, 105479. doi:10.1016/j.phrs.2021.105479

10. Faraone, I., Sinisgalli, C., Ostuni, A., Armentano, M. F., Carmosino, M., Milella, L., Russo, D., Labanca, F., \& Khan, H. (2020). Astaxanthin anticancer effects are mediated through multiple molecular mechanisms: A systematic review. Pharmacol Res, 155, 104689. doi:10.1016/j.phrs.2020.104689

11. Feng, Y., Chu, A., Luo, Q., Wu, M., Shi, X., \& Chen, Y. (2018). The Protective Effect of Astaxanthin on Cognitive Function via Inhibition of Oxidative Stress and Inflammation in the Brains of Chronic T2DM Rats. Front Pharmacol, 9, 748. doi:10.3389/fphar.2018.00748

12. Hormozi, M., Ghoreishi, S., \& Baharvand, P. (2019). Astaxanthin induces apoptosis and increases activity of antioxidant enzymes in LS-180 cells. Artif Cells Nanomed Biotechnol, 47(1), 891-895. doi:10.1080/21691401.2019.1580286

13. Kavitha, K., Kowshik, J., Kishore, T. K., Baba, A. B., \& Nagini, S. (2013). Astaxanthin inhibits NF-KB and Wnt/ $\beta$-catenin signaling pathways via inactivation of Erk/MAPK and PI3K/Akt to induce intrinsic apoptosis in a hamster model of oral cancer. Biochim Biophys Acta, 1830(10), 4433-4444. doi:10.1016/j.bbagen.2013.05.032

14. Kim, H.-Y., Kim, Y.-M., \& Hong, S. (2019a). Astaxanthin suppresses the metastasis of colon cancer by inhibiting the MYC-mediated downregulation of microRNA-29a-3p and microRNA-200a. Scientific Reports, 9(1), 9457. doi:10.1038/s41598-019-45924-3

15. Kim, S. H., Lim, J. W., \& Kim, H. (2019b). Astaxanthin Prevents Decreases in Superoxide Dismutase 2 Level and Superoxide Dismutase Activity in Helicobacter pylori-infected Gastric Epithelial Cells. 
Journal of cancer prevention, 24(1), 54-58. doi:10.15430/JCP.2019.24.1.54

16. Ko, J.-C., Chen, J.-C., Wang, T.-J., Zheng, H.-Y., Chen, W.-C., Chang, P.-Y., \& Lin, Y.-W. (2016). Astaxanthin down-regulates Rad51 expression via inactivation of AKT kinase to enhance mitomycin C-induced cytotoxicity in human non-small cell lung cancer cells. Biochemical Pharmacology, 105, 91-100. doi:https://doi.org/10.1016/j.bcp.2016.02.016

17. Kowshik, J., Nivetha, R., Ranjani, S., Venkatesan, P., Selvamuthukumar, S., Veeravarmal, V., \& Nagini, S. (2019). Astaxanthin inhibits hallmarks of cancer by targeting the PI3K/NF-KB/STAT3 signalling axis in oral squamous cell carcinoma models. IUBMB Life, 71(10), 1595-1610. doi:10.1002/iub.2104

18. Kurihara, H., Koda, H., Asami, S., Kiso, Y., \& Tanaka, T. (2002). Contribution of the antioxidative property of astaxanthin to its protective effect on the promotion of cancer metastasis in mice treated with restraint stress. Life Sci, 7O(21), 2509-2520. doi:10.1016/s0024-3205(02)01522-9

19. Liu, X., Song, M., Gao, Z., Cai, X., Dixon, W., Chen, X., Cao, Y., \& Xiao, H. (2016). Stereoisomers of Astaxanthin Inhibit Human Colon Cancer Cell Growth by Inducing G2/M Cell Cycle Arrest and Apoptosis. J Agric Food Chem, 64(41), 7750-7759. doi:10.1021/acs.jafc.6b03636

20. Lococo, F. (2021). Malignant Pleural Mesothelioma: Time Is Running Out. J Clin Med, 10(4). doi: $10.3390 / \mathrm{jcm} 10040648$

21. McCall, B., McPartland, C. K., Moore, R., Frank-Kamenetskii, A., \& Booth, B. W. (2018). Effects of Astaxanthin on the Proliferation and Migration of Breast Cancer Cells In Vitro. Antioxidants (Basel, Switzerland), 7(10), 135. doi:10.3390/antiox7100135

22. Meng, H.-Z., Ni, X.-F., Yu, H.-N., Wang, S.-S., \& Shen, S.-R. (2017). Effects of astaxanthin on oxidative stress induced by $\mathrm{Cu}(2+)$ in prostate cells. Journal of Zhejiang University. Science. B, 18(2), 161-171. doi:10.1631/jzus.B1500296

23. Patel, S. C., \& Dowell, J. E. (2016). Modern management of malignant pleural mesothelioma. Lung Cancer (Auckl), 7, 63-72. doi:10.2147/lctt.S83338

24. Simioni, C., Zauli, G., Martelli, A. M., Vitale, M., Sacchetti, G., Gonelli, A., \& Neri, L. M. (2018). Oxidative stress: role of physical exercise and antioxidant nutraceuticals in adulthood and aging. Oncotarget, 9(24), 17181-17198. doi:10.18632/oncotarget.24729

25. Sowmya, P. R., Arathi, B. P., Vijay, K., Baskaran, V., \& Lakshminarayana, R. (2017). Astaxanthin from shrimp efficiently modulates oxidative stress and allied cell death progression in MCF-7 cells treated synergistically with $\beta$-carotene and lutein from greens. Food Chem Toxicol, 106(Pt A), 58-69. doi:10.1016/j.fct.2017.05.024

26. Su, X. Z., Chen, R., Wang, C. B., Ouyang, X. L., Jiang, Y., \& Zhu, M. Y. (2019). Astaxanthin Combine with Human Serum Albumin to Abrogate Cell Proliferation, Migration, and Drug-resistant in Human Ovarian Carcinoma SKOV3 Cells. Anticancer Agents Med Chem, 19(6), 792-801. doi:10.2174/1871520619666190225123003

27. Wen, X., Huang, A., Hu, J., Zhong, Z., Liu, Y., Li, Z., Pan, X., \& Liu, Z. (2015). Neuroprotective effect of astaxanthin against glutamate-induced cytotoxicity in HT22 cells: Involvement of the Akt/GSK-3 $\beta$ pathway. Neuroscience, 303, 558-568. doi:10.1016/j.neuroscience.2015.07.034 
28. Wolf, A. M., Asoh, S., Hiranuma, H., Ohsawa, I., lio, K., Satou, A., Ishikura, M., \& Ohta, S. (2010). Astaxanthin protects mitochondrial redox state and functional integrity against oxidative stress. $J$ Nutr Biochem, 21(5), 381-389. doi:10.1016/j.jnutbio.2009.01.011

29. Wu, C., Zhang, J., Liu, T., Jiao, G., Li, C., \& Hu, B. (2016). [Astaxanthin inhibits proliferation and promotes apoptosis of A549 lung cancer cells via blocking JAK1/STAT3 pathway]. Xi Bao Yu Fen Zi Mian Yi Xue Za Zhi, 32(6), 784-788.

30. Yan, T., Li, H. Y., Wu, J. S., Niu, Q., Duan, W. H., Han, Q. Z., Ji, W. M., Zhang, T., \& Lv, W. (2017). Astaxanthin inhibits gemcitabine-resistant human pancreatic cancer progression through EMT inhibition and gemcitabine resensitization. Oncol Lett, 14(5), 5400-5408. doi:10.3892/ol.2017.6836

31. Zhang, X., Zhao, W. E., Hu, L., Zhao, L., \& Huang, J. (2011). Carotenoids inhibit proliferation and regulate expression of peroxisome proliferators-activated receptor gamma (PPARY) in K562 cancer cells. Arch Biochem Biophys, 512(1), 96-106. doi:10.1016/j.abb.2011.05.004

\section{Figures}

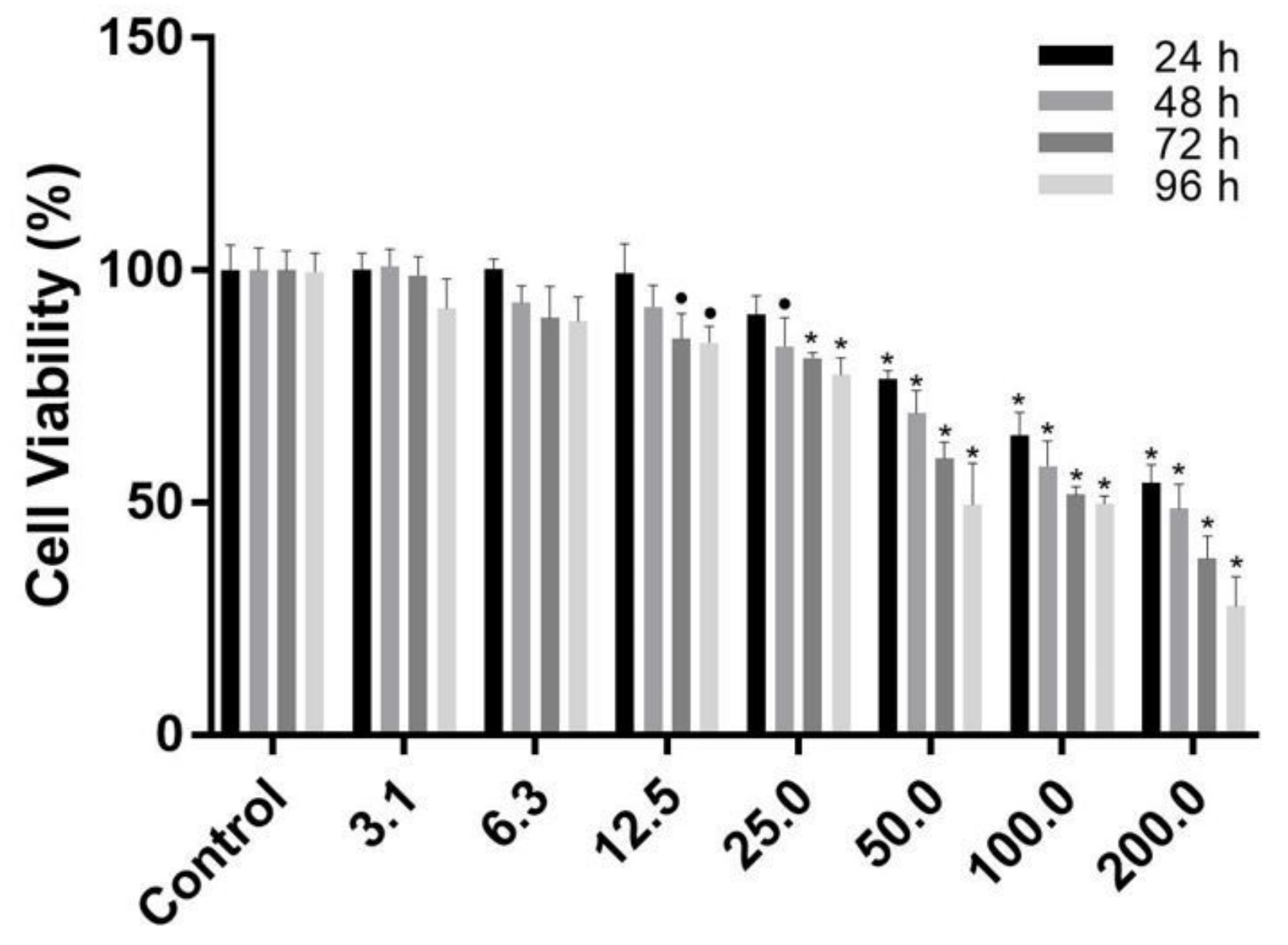


Figure 1

MTT Assay. The changes in cell viability (\%) of SPC212 cells with varying ASX doses $(24,48,72$ and 96 h-long assays). "•" and "*" designate significant difference of $p<0.05$ and $p<0.001$, respectively when compared to the correspondent control
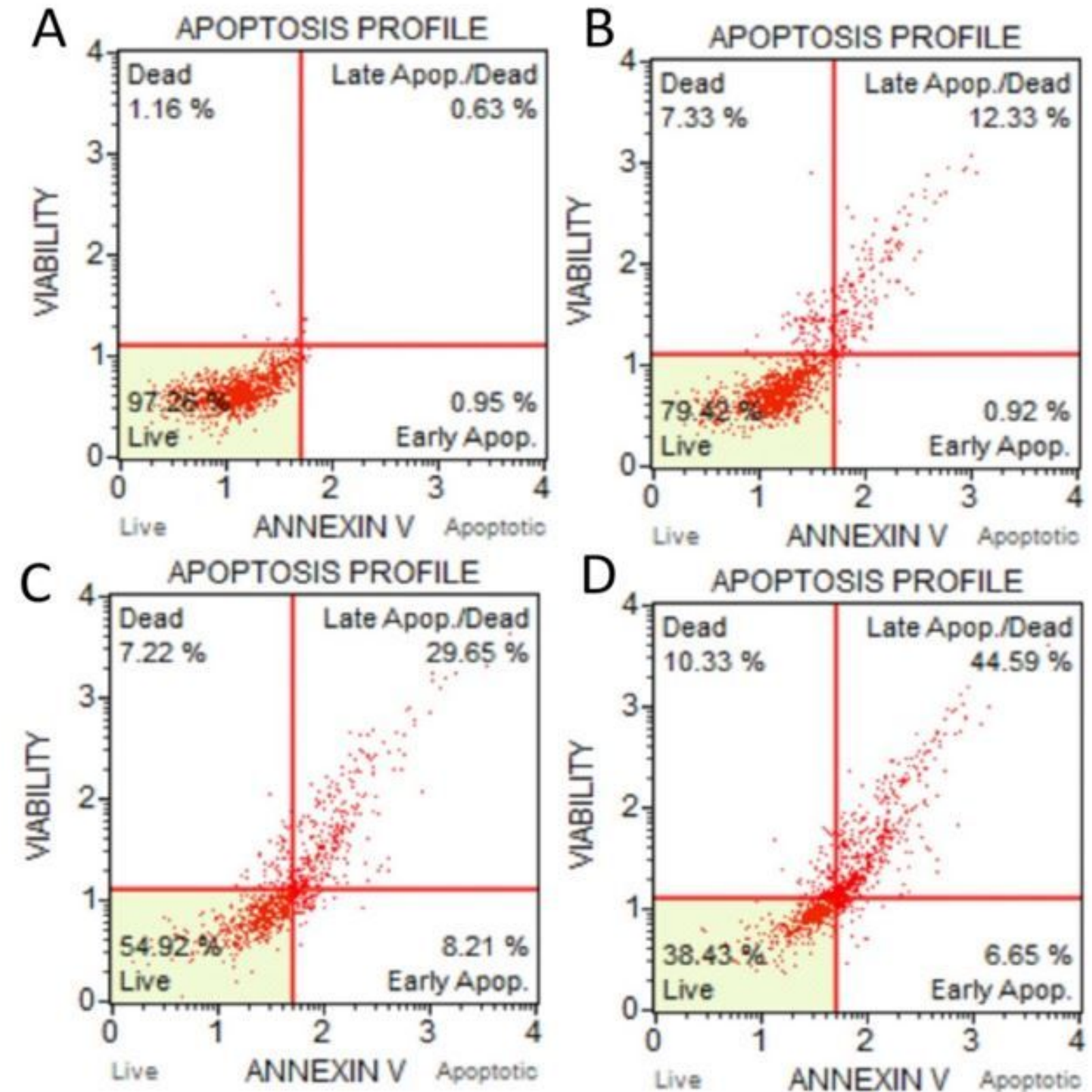

\section{Figure 2}

Annexin V results of the ASX-treated cells. A: untreated cells, B: $50 \mu \mathrm{M}$ of ASX-treated cells, C: $100 \mu \mathrm{M}$ of ASX-treated cells, D: $200 \mu \mathrm{M}$ of ASX-treated cells. 

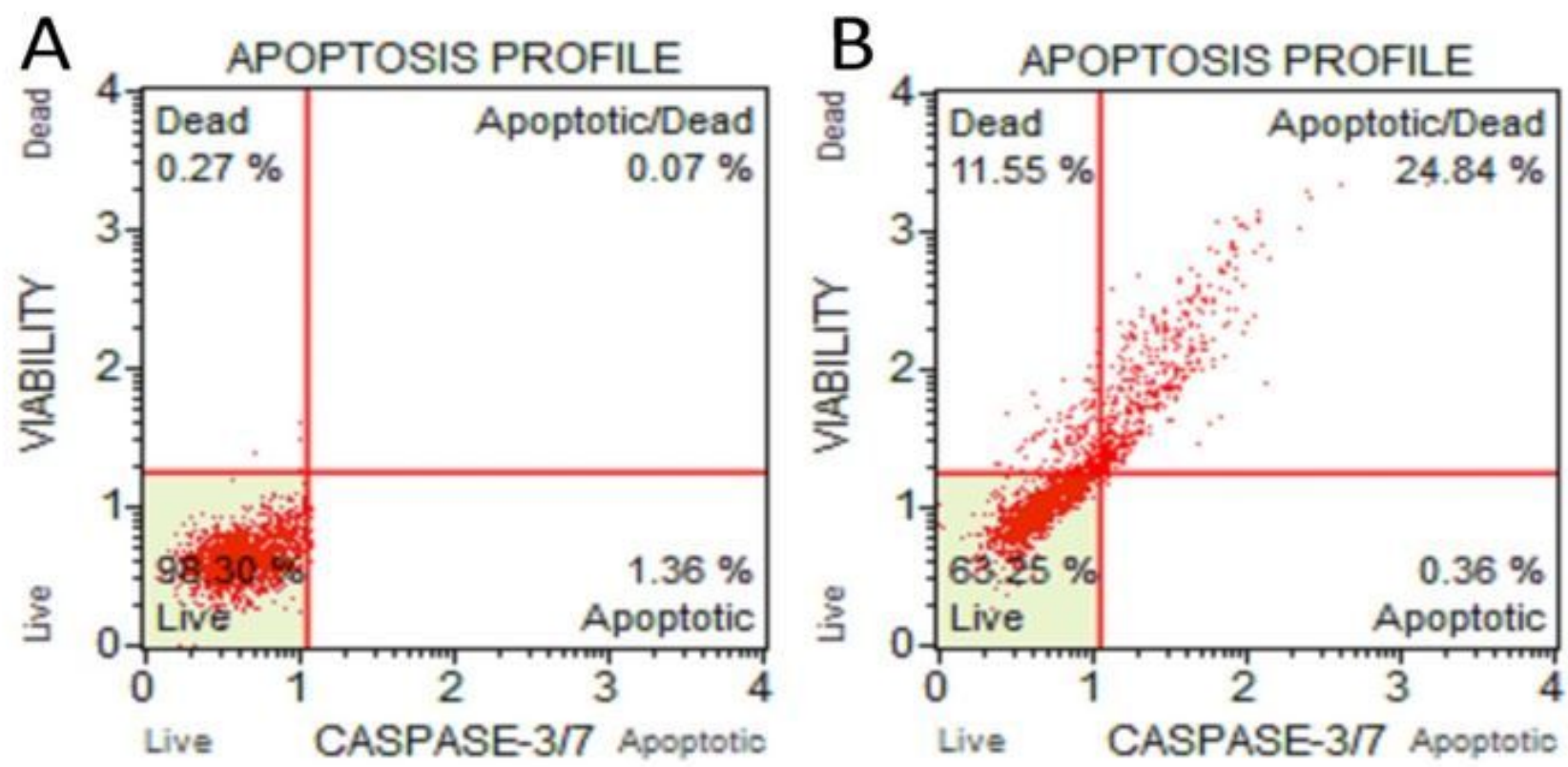

Live CASPASE-3/7 Apoptotic

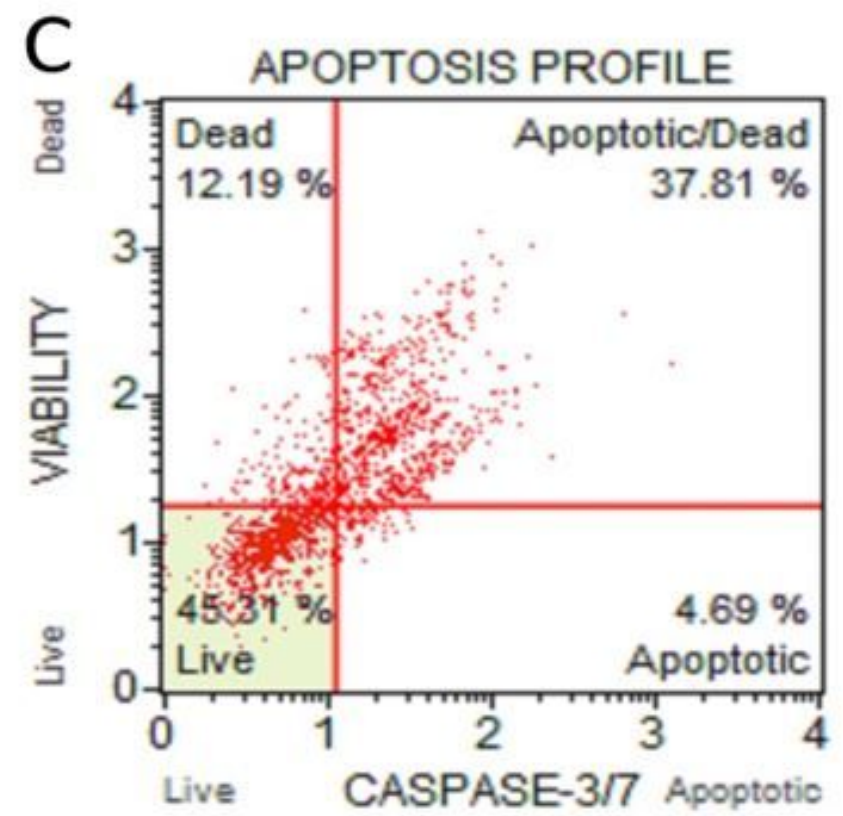

Figure 3

Caspase 3/7 results of the ASX-treated cells. A: untreated cells, B: $100 \mu \mathrm{M}$ of ASX-treated cells, C: $200 \mu \mathrm{M}$ of ASX-treated cells. 

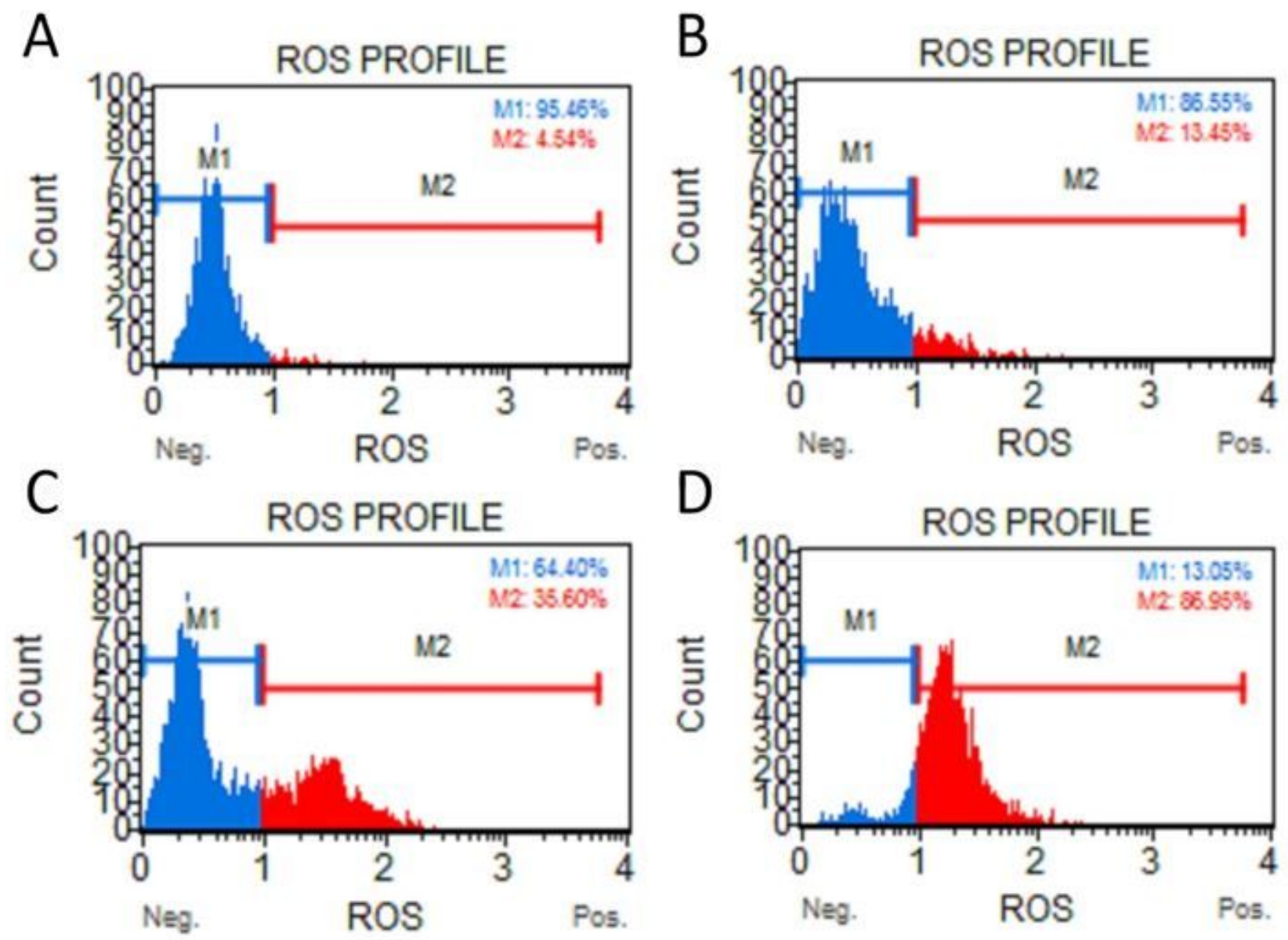

Figure 4

Oxidative stress results. A: untreated cells, B: $50 \mu \mathrm{M}$ of ASX-treated cells, C: $100 \mu \mathrm{M}$ of ASX-treated cells, D: $200 \mu \mathrm{M}$ of ASX-treated cells. 


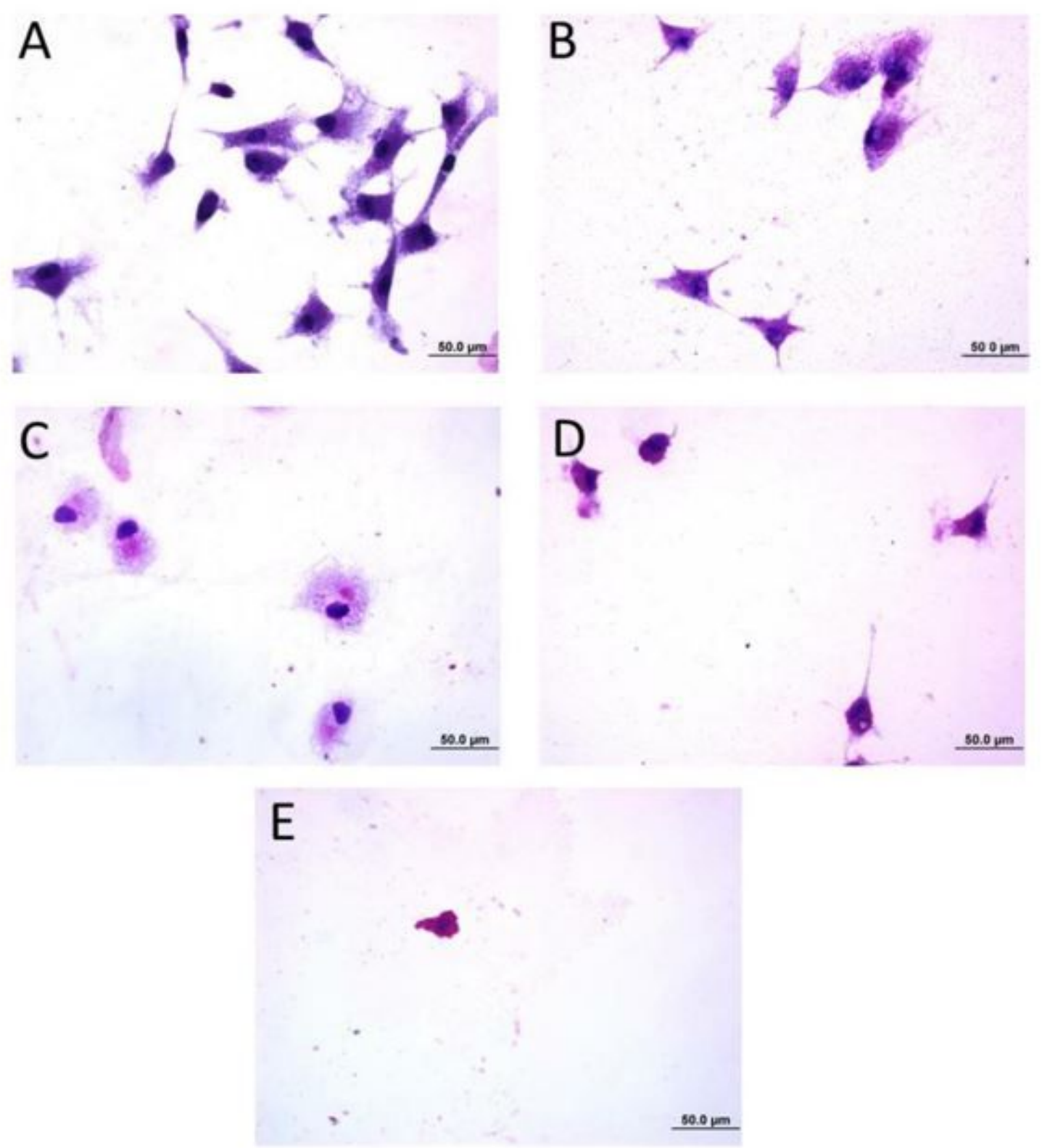

\section{Figure 5}

The hematoxylin-eosin migrographs of SPC212 cells. A: untreated cells, B: $50 \mu \mathrm{M}$ of ASX -treated cells. C: $100 \mu \mathrm{M}$ of ASX-treated cells. Note of vacuole-like structures and cell swelling. Shrunk cells with eccentric nuclei. D: $200 \mu \mathrm{M}$ of ASX-treated cells. E: $300 \mu \mathrm{M}$ of ASX-treated cells. Note of membrane blebbing and evidently acidophilic cytoplasm. Bar scales indicate $50.0 \mu \mathrm{m}$. 